American J. of Engineering and Applied Sciences 4 (3): 350-354, 2011

ISSN 1941-7020

(C) 2014 Tsolakis and Raptis, This open access article is distributed under a Creative Commons Attribution

(CC-BY) 3.0 license

\title{
Comparison of Maximum Gear-Tooth Operating Bending Stresses Derived from Niemann's Analytical Procedure and the Finite Element Method
}

\author{
Andonios D. Tsolakis and Konstandinos G. Raptis \\ Department of Mechanical Engineering, \\ Technological Education Institute of Piraeus, \\ School of Applied Sciences and Technology, \\ 250 Thivon and P. Ralli, 12244, Egaleo, Greece
}

\begin{abstract}
Problem statement: Main purpose of this study was to investigation toothed gear loading problems using the Finite Element Method. Approach: We used Niemann's equations to compare maximum bending stress which was developed at critical gear-tooth flank point during gear meshing, applied for three distinct spur-gear sizes, each having different teeth number, module and power rating. Results: The results emerging after the application of Niemann's equations were compared to the results derived by application of the Finite Element Method (FEM) for the same gear-loading input data. Results were quite satisfactory, since von Mises' equivalent stresses calculated with FEM were of the same order with the results of classical analytical method. Conclusion: Judging from the emerging results, deviation of the two methods, analytical (Niemann's equations) and computational (FEM), referring to maximum bending stress is fairly slight, independently of the applied geometrical and loading data of each gear.
\end{abstract}

Key words: Loaded gears, strength estimation, Finite Element Method (FEM), gear-tooth strength, critical point, geometrical properties, Niemann's Analytical, Niemann's method, single teeth pair, systematic investigation

\section{INTRODUCTION}

Finite element method: One of the earliest applications of the Finite Element Method.is attributed to Hrenikoff 1941 and Raptis et al. (2010) in 1941, who presented an early method interpretation after replacement of a plane elastic means with an apparatus consisted of bars and beams. Courant (1943) applied piecewise polynomial interpolation on triangular subdomains in order to investigate torsion problems. "Finite Elements" term occurred first in 1960 and was used by Clough (1960). Mathematical foundations were developed during the decade between 1960 and 1970 and include the invention of novel elements types, convergence studies and other related research.

Some of the most famous computational methods for engineering problem solving are the variational methods, which include Rayleigh-Ritz method (Pierce and Varga, 1972) and the methods of weighted residuals, one of which is Galerkin's method (Belytschko et al., 1994). The Finite Element Method can be assumed as a special formulation of RayleighRitz (Pierce and Varga, 1972) and weighted residuals methods, which is advantageous compared to the early formulations of the later due to the greater convenience with which it resolves complex geometries.

Classical approach to gear-tooth strength estimation: The first systematic investigation for geartooth critical point location is attributed to Lewis (1882), who assumed that the inscribed isosceles parabola which osculates internally with gear-tooth profile at tooth root defines the critical point exactly as the point of tangency of parabola with tooth profile at the tension side of the tooth.

Furthermore, an alternative method is the one of 30-degree inclined tangent, which assumes that critical point does not depend on the application point of gear load, but it occurs at a fixed location at gear-tooth root. This method, although adopted by DIN 39901987 and ISO 63361996 standards, is approximate and valid only for lightly loaded gears.

According to DIN 39901987 method, calculation of bending stresses at gear-tooth root is based on $30^{\circ}$ inclined tangent theory (Niemann and Winter, 1985), a fact that constitutes a disadvantage of this approximate method which is inappropriate for heavily loaded gearings.

Corresponding Author: Andonios D. Tsolakis, Department of Mechanical Engineering, Technological Education Institute of Piraeus, School of Applied Sciences and Technology, 250 Thivon and P. Ralli, 12244, Egaleo, Greece 


\section{MATERIALS AND METHODS}

The aforementioned methods for the implementation of finite elements calculations will not be applied because calculation of necessary geometrical properties is a time-consuming procedure, while calculation of normal stress at maximum loading point will be represented by von Mises' equivalent stress.

Gear-tooth bending strength estimation according to the classical theory: Gear strength calculations will be conducted separately for pinion and gear. We assume that gear-tooth can be modeled as a cantilever beam and calculate stresses at gear-tooth root resulting from gear meshing load $F_{n}$. After decomposing $F_{n}$ in two components, on tangential and radial directions respectively, the first acts as a perpendicular load causing bending and shearing, while the later causes compression. Consequently, gear-tooth supports three kinds of stresses, namely bending, compressive and shearing stresses, as shown in Fig. 1. Since overlap coefficient is greater than unity $(\varepsilon>1)$, for a specified time period during gear meshing two pairs of gear teeth are simultaneously in contact, while at this period operating load $F_{n}$ is split to both gear-teeth pairs. From Fig. 2 is obvious that:

A is contact point at pinion tooth root. This is the point where teeth contact initiates and $F_{n}$ is split to both teeth pairs,

$\mathrm{B}$ is an intermediate point where contact exists only between a single teeth pair.

Dual teeth pair contact is completed at point $\mathrm{E}$ and onwards the working load $F_{n}$ is transmitted only by a single teeth pair at point $\mathrm{B}$.

Equations for gear-tooth strength estimation: For example, $\mathrm{s}_{\mathrm{F}}$, at tooth root (Fig. 1), which is inserted in the following equations, can be estimated using either 30-degree inclined tangent method or any other appropriate method. Bending strength calculation of gear tooth is given by the following Eq. 1-4:

$\sigma_{\mathrm{F}}=\frac{\mathrm{F}_{\mathrm{u}}}{\mathrm{b} \cdot \mathrm{m}} \cdot \mathrm{Y}_{\mathrm{F}} \cdot \mathrm{Y}_{\varepsilon} \cdot \mathrm{K}_{\mathrm{F} \alpha} \leq \sigma \mathrm{F}_{\varepsilon \pi}$

Normal gear load $\mathrm{F}_{\mathrm{u}}$ :

$\mathrm{F}_{\mathrm{u}}=\frac{2 \cdot \mathrm{M}_{\mathrm{t}}}{\mathrm{d}_{0}}$

Torsion moment (torque) $\mathrm{M}_{\mathrm{t}}$ :

$\mathrm{M}_{\mathrm{t}}=\frac{\mathrm{P}}{2 \cdot \pi \cdot \mathrm{n}}$

Gear tooth length b:

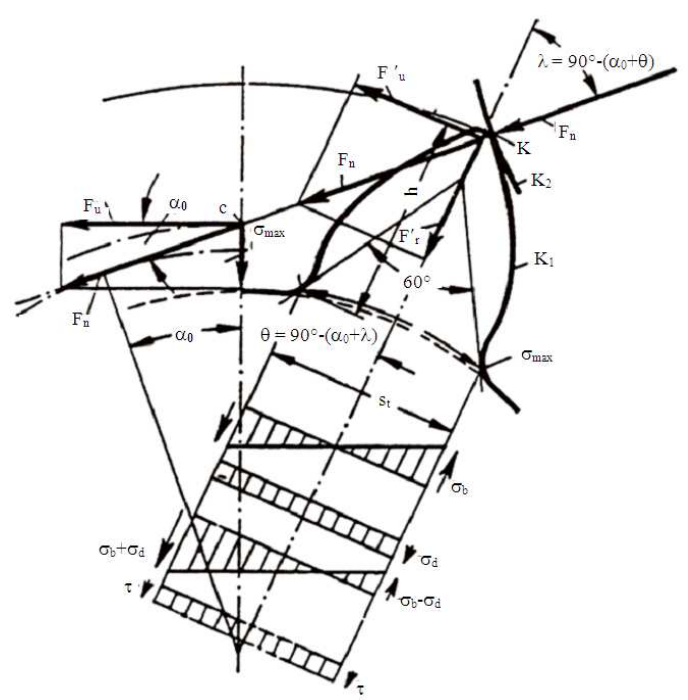

Fig. 1: Gear-tooth root loading

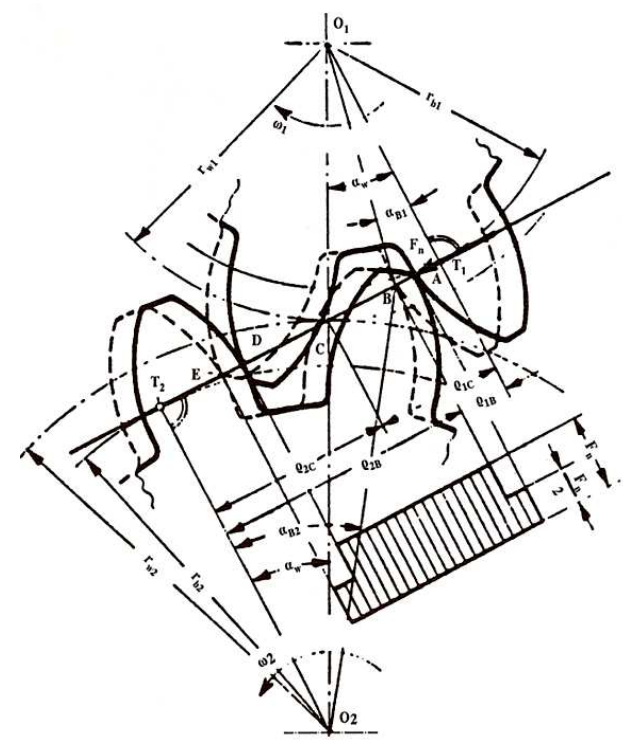

Fig. 2: Points of single contact at external gearing

$\mathrm{b}=\mathrm{m} \cdot \lambda$

Where:

$\lambda=$ Factor of direction depended on gearing quality and bearing design

$Y_{F}=$ Tooth-profile shape coefficient depended on displacement factor and gear teeth number

$\mathrm{Y}_{\varepsilon}=$ Overlap factor

$\mathrm{K}_{\mathrm{F} \alpha}=$ Load distribution coefficient depended on gearing quality 
Am. J. Engg. \& Applied Sci., 4 (3): 350-354, 2011

Table 1: Analytical data for each distinct gear

\begin{tabular}{lllllllll}
\hline & $\mathrm{m}$ & $\mathrm{b}_{1}$ & & $\mathrm{P}$ & $\mathrm{n}$ & $\mathrm{F}_{\mathrm{u}}$ & $\mathrm{M}_{\mathrm{t}}$ & $\sigma_{\mathrm{F}}$ \\
$\mathrm{z}_{1}$ & $(\mathrm{~mm})$ & $(\mathrm{mm})$ & $\mathrm{Y}_{\mathrm{F}}$ & $(\mathrm{KW})$ & $\begin{array}{l}\mathrm{rpm}) \\
(\mathrm{Nt})\end{array}$ & $(\mathrm{Nm})$ & $\left(\mathrm{N} \mathrm{mm}^{-2}\right)$ \\
\hline 18 & 6 & 162 & 3.02 & 18 & 1250 & 2548 & 137.6 & 7.900 \\
20 & 10 & 178 & 2.91 & 20 & 1450 & 2636 & 131.8 & 4.300 \\
22 & 8 & 149 & 2.87 & 16 & 1250 & 1389 & 122.3 & 3.346 \\
\hline
\end{tabular}

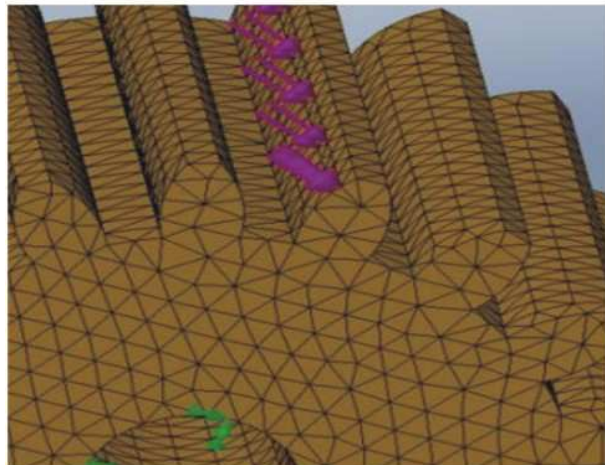

Fig. 3: Modeling of gear No.1

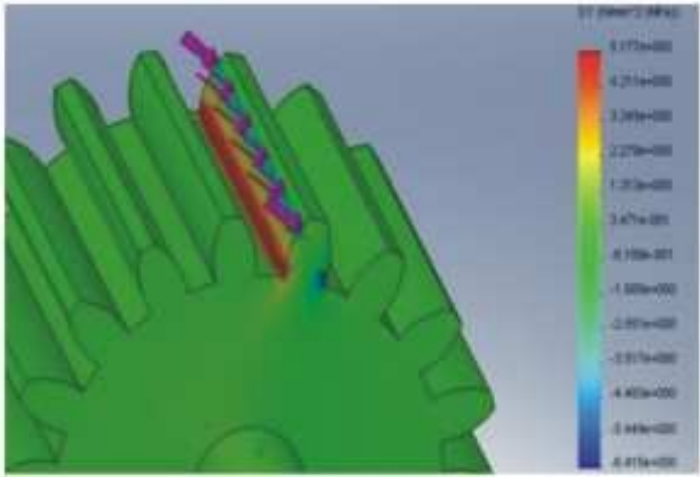

Fig. 4: Maximum normal stress of gear No.1 at ydirection (maximum bending stress) $\left(\sigma_{\mathrm{y}}=5,177\right.$ $\mathrm{Nm} \mathrm{m}^{-2}$ )

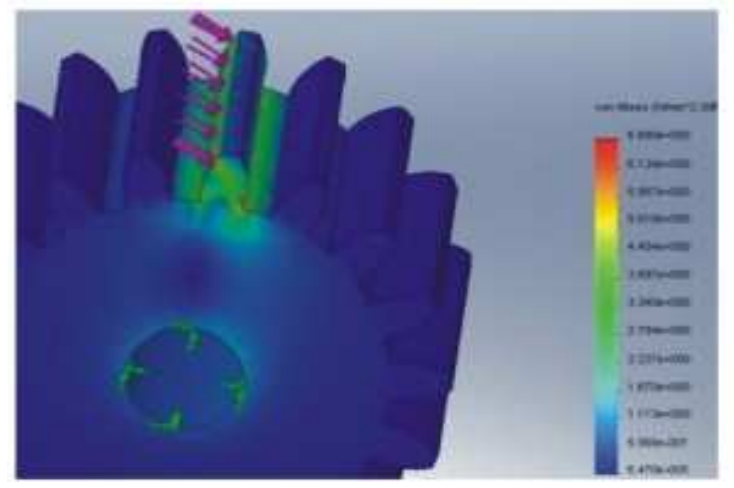

Fig. 5: Von Mises' equivalent stress of gear No.1 (6,680 $\mathrm{N} \mathrm{m} \mathrm{m}^{-2}$ )

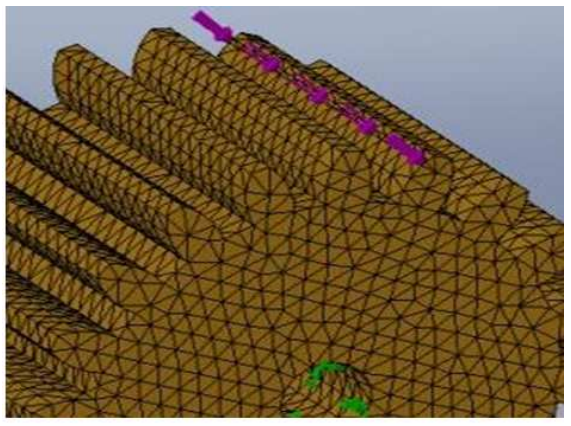

Fig. 6: Modeling of gear No.2

Application of Niemann's equations: We will investigate if results from the application of maximumstress equations from the concurrent bibliography (1965), meet the results of Finite Element Method (FEM) application.

For this reason we choose three different gear materials, like Ck - 45 (gear No.1), AISI 1045 (gear No.2) and Ck- 60 (gear No.3) steels, combined with arbitrarily selected values for the following parameters:

Gear teeth numbers:

$\mathrm{z}=18,20 \kappa \alpha \mathrm{l} 22$

Module:

$\mathrm{m}=10,6 \kappa \alpha_{1} 8 \mathrm{~mm}$

Tooth length:

$\mathrm{b}_{1}=162,178 \kappa \alpha 149 \mathrm{~mm}$

Input power:

$\mathrm{P}_{\mathrm{W}}=18,20 \kappa \alpha 16 \mathrm{~kW}$

In the Table 1 , concentrates all analytical input data for each distinct gear.

Application of the finite element method: Furthermore, each gear with involute gear-tooth profile is modeled with finite elements through the implementation of CAD and FEM tools (Fig. 3, 6 and 9). A finite element mesh is thus created which is then refined as much possible. The corresponding normal load is then applied on a single gear tooth. Results from the application of load at maximum loading position for each gear can be seen at the respective figures, namely maximum normal stresses $\left(\sigma_{y}\right)$ at Fig. 4, 7 and 10 and for von Mises' equivalent stresses at Fig. 5, 8 and 11. Maximum normal stress $\left(\sigma_{\mathrm{y}}\right)$ occurs at geartooth root at the side of normal load application. 


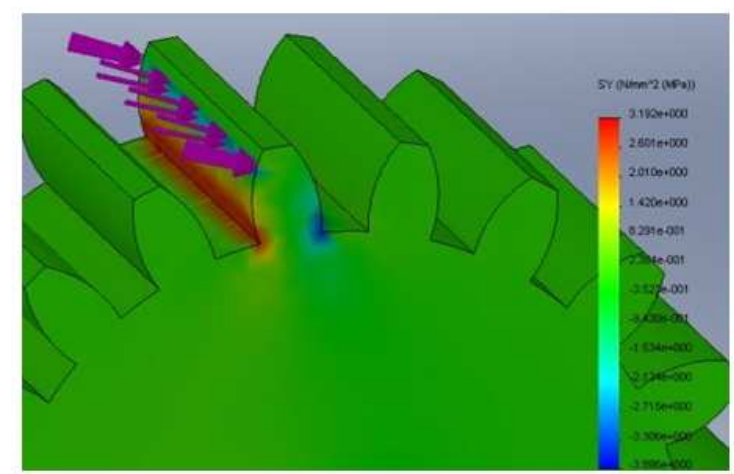

Fig. 7: Maximum normal stress of gear No.2 at ydirection (maximum bending stress) $\left(\sigma_{\mathrm{y}}=3,192\right.$ $\mathrm{N} \mathrm{m} \mathrm{m}{ }^{-2}$ )

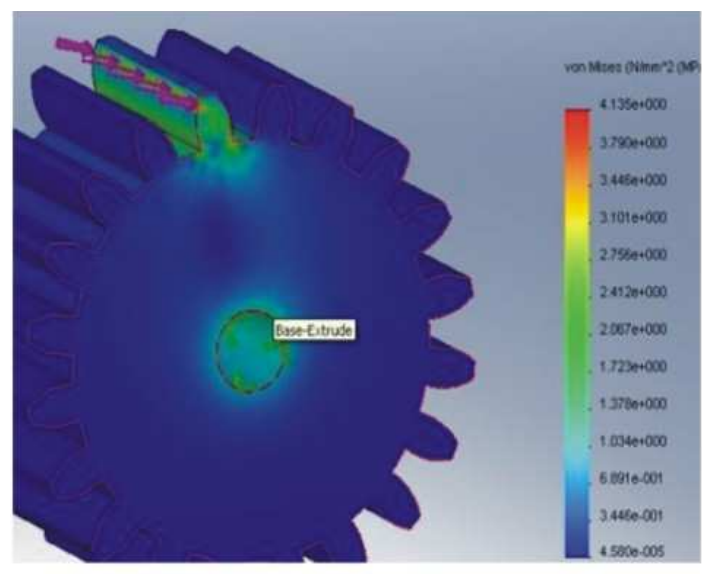

Fig. 8: Von Mises' equivalent stress of gear No.2 $\left(4,135 \mathrm{~N} \mathrm{~m} \mathrm{~m}^{-2}\right)$

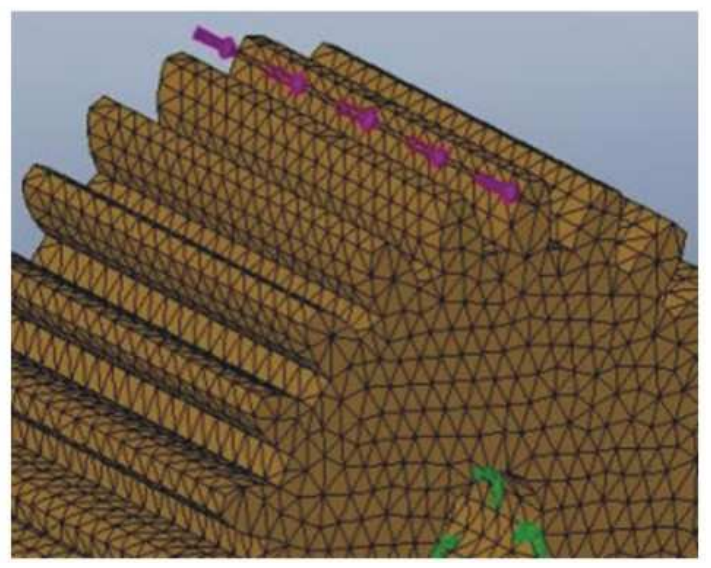

Fig. 9: Modeling of gear No.3

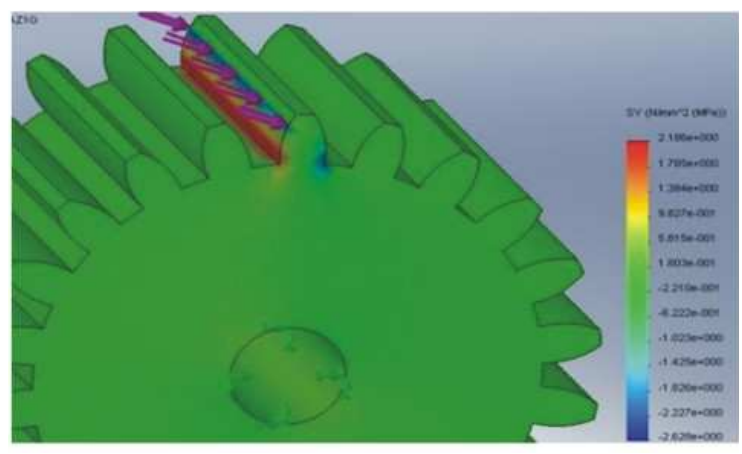

Fig. 10: Maximum normal stress of gear No.3 at ydirection (maximum bending stress) $\left(\sigma_{\mathrm{y}}=\right.$ 2,186 $\mathrm{N} \mathrm{m} \mathrm{m}^{-2}$ )

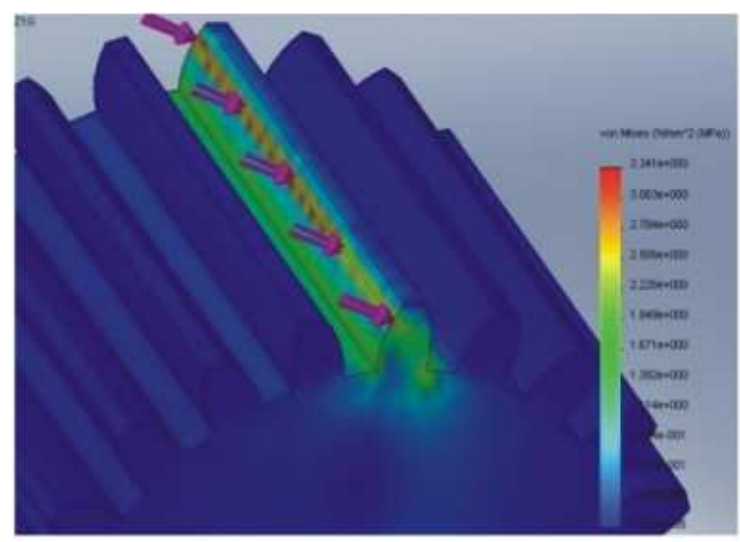

Fig. 11: Von Mises' equivalent stress of gear No.3 $\left(3,341 \mathrm{~N} \mathrm{~m} \mathrm{~m}^{-2}\right)$

\section{RESULTS}

Although classical Niemann's method, which was applied, calculates bending stresses, it covers not only the respective bending stress that we estimated using FEM, but also the equivalent von Mises' stress.

This fact is explained if we take into account that Finite Element Method is a much more advanced and accurate method compared to Niemann's one. This also constitutes a criterion for the correctness of our results, as classical analytical method should provide overestimated results compared to that of FEM's and furthermore the calculated equivalent von Mises' stresses should be of the same order with Niemann's results.

Results are concentrated at the Table 2.

From the above results, we conclude that the classical method of bending strength estimation gives results overestimated compared to FEM's results concerning both normal stresses $\sigma_{\mathrm{y}}$ and von Mises' equivalent stresses. 
Am. J. Engg. \& Applied Sci., 4 (3): 350-354, 2011

Table 2: Results and concentrated

\begin{tabular}{llll}
\hline & FEM results & $\begin{array}{l}\text { Niemann's } \\
\text { Analytical results }\end{array}$ \\
Gear No. & $\sigma_{\mathrm{y}}\left(\mathrm{N} \mathrm{mm}^{-2}\right)$ & von Mises $\left(\mathrm{N} \mathrm{mm}^{-2}\right)$ & $-\sigma_{\mathrm{F}}\left(\mathrm{N} \mathrm{mm}^{-2}\right)$ \\
\hline 1 & 5.177 & 6.680 & 7.900 \\
2 & 3.192 & 4.135 & 4.300 \\
3 & 2.186 & 3.341 & 3.346 \\
\hline
\end{tabular}

Results are quite satisfactory, since von Mises' equivalent stresses calculated with FEM are of the same order with the results of classical analytical method.

Finite Element Method solves numerous problems from the fields of solid and fluid mechanics, heat transfer, electromagnetic and many other areas, due to its accuracy without the need for time-consuming and expensive experimental test, in many occasions.

\section{DISCUSSION}

Apart from solid mechanics failure, it has been noticed that cracks are developed on gear-tooth flank due to surface fatigue caused by high contact pressure at the neighborhood of pitch point where the whole working load is transmitted by a single gear teeth pair. Fine lubricants can enter these initially small cracks and apply high hydraulic pressure during operation which further propagates cracks resulting to surface pitting.

For this reason it is very important to check surface fatigue strength of gears. Future study should investigate the accurate location of load application which results to maximum gear-tooth stresses, as well as its maximum value that a gear can withstand in connection with geometrical and mechanical properties of gear (Raptis et al., 2010).

\section{CONCLUSION}

In this study we ascertained minimal divergence of maximum bending stress of gear-teeth occurring during gear meshing, applied for different spur gear materials, gear-teeth numbers, modules and power ratings, after the application of Niemann's equations at maximum bending stress location and the Finite Elements Method (FEM).
After comparing the results of the aforementioned methods applied for many different case studies, it was concluded that their values have acceptable divergence, which is normally expected, since the difference between normal stresses $\sigma_{\mathrm{y}}$ and $\sigma_{\mathrm{F}}$ is regularly greater than the difference between $\sigma_{\mathrm{F}}$ and von Mises's equivalent stresses, because safety factors are taken into account when applying Niemann's method. This results in a bending stress value greater than von Mises' equivalent stress, which in turn is always greater than normal stress $\sigma_{\mathrm{y}}$.

\section{REFERENCES}

Belytschko, T., Y.Y. Lu and L. Gu, 1994. ElementFree Galerkin Methods. Int. J. Numerical Meth. Eng., 37: 229-256. DOI: 10.1002/nme.1620370205

Clough, R.W., 1960. The finite element method in plane stress analysis. Proceedings of the 2nd Conference on Electronic Computation, (EC' 06), CSA, Pittsburgh. http://md1.csa.com

Courant, R., 1943. Variational methods for the solution of problems of equilibrium and vibrations. Bull. Am. Math. Soc., 49: 1-23. DOI: 10.1090/S00029904-1943-07818-4

Lewis, W., 1882. Investigation of strenght of gear teeth. Gear Technol. http://md1.csa.com

Niemann, G. and H. Winter, 1985. Maschinelemente, Band 2: Getriebe allgemein, Zahnradgetriebe, Grundlagen and Stirnradgetriebe. 2nd Edn., Springer, Berlin, ISBN-10: 3540111492, pp: 376.

Pierce, J.G. and R.S. Varga, 1972. Higher order convergence results for the Rayleigh-Ritz method applied to Eigenvalue problems. I: Estimates relating Rayleigh-Ritz and Galerkin approximations to Eigenfunctions. SIAM J. Numer. Anul., 9: 137-151.

Raptis, K.G., T.N. Costopoulos, G.A. Papadopoulos and A.D. Tsolakis, 2010. Rating of spur gear strength using photoelasticity and the finite element method. Am. J. Eng. Applied Sci., 3: 222231. DOI: 10.3844 /ajeassp.2010.222.231 